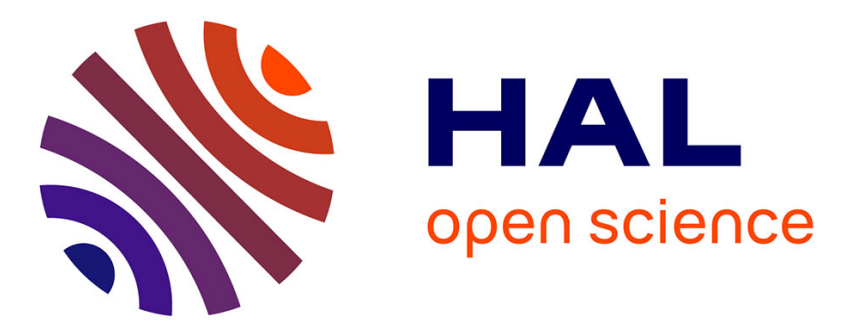

\title{
Robust control of four-phase interleaved boost converter by considering the performance of PEM fuel cell current
}

Xinyang Hao, Issam Salhi, Salah Laghrouche, Youcef Ait Amirat, Abdesslem

Djerdir

\section{- To cite this version:}

Xinyang Hao, Issam Salhi, Salah Laghrouche, Youcef Ait Amirat, Abdesslem Djerdir. Robust control of four-phase interleaved boost converter by considering the performance of PEM fuel cell current. International Journal of Hydrogen Energy, 2021, 46 (78), pp.38827 - 38840 . hal-03456151

\section{HAL Id: hal-03456151 \\ https://hal.science/hal-03456151}

Submitted on 29 Nov 2021

HAL is a multi-disciplinary open access archive for the deposit and dissemination of scientific research documents, whether they are published or not. The documents may come from teaching and research institutions in France or abroad, or from public or private research centers.
L'archive ouverte pluridisciplinaire HAL, est destinée au dépôt et à la diffusion de documents scientifiques de niveau recherche, publiés ou non, émanant des établissements d'enseignement et de recherche français ou étrangers, des laboratoires publics ou privés. 


\title{
Robust Control of Four-Phase Interleaved Boost Converter by
}

\section{Considering the performance of PEM Fuel Cell Current}

\author{
Xinyang Hao, Issam Salhi, Salah Laghrouche, Youcef Ait Amirat, Abdesslem Djerdir \\ FEMTO-ST Institute, Univ. Bourgogne Franche-Comté, UTBM, CNRS \\ Rue Ernest Thierry Mieg, F-90000 Belfort, France.
}

\begin{abstract}
Hydrogen associated with Proton Exchange Membrane Fuel Cell (PEMFC) as the prime candidate energy is becoming attention in transportation. However, the cost and the service lifespan are the main reasons that limit PEMFC wide application. In this paper, the super-twisting sliding mode (STSM) controller is designed for a four-phase interleaved boost converter (IBC) coupled with a PEMFC. The proposed controller can enhance the robustness of the output voltage while reducing the PEMFC current overshoot as much as possible for protection under a certain limitation of the PEMFC current ripple. The stability of the proposed controller is proved by the Lyapunov theorem. A typical proportionalintegral (PI) controller based on ac small-signal model is designed for further comparison and discussion. The effectiveness of the STSM controller is further evaluated through experimental results obtained with a $1 \mathrm{~kW}$ fuel cell system based on a real-time hardware-in-the-loop system.
\end{abstract}

Keywords - Proton exchange membrane fuel cell, Interleaved boost converter, Fuel cells current, Super-twisting sliding mode control.

\section{Introduction}

Fossil fuel as the major power source has been widely used in the field of infrastructure, transportation, economy and standard of life for nearly hundreds of years. Today, the proportion of fossil fuels are still high. It is predicted that it will represent approximately $75 \%$ of energy production in 2050 [1]. However, due to the shortage and emissions pollution of fossil fuel, many sustainable energy sources, like wind, solar and hydrogen have been closely valued. Over the last two decades, vehicles have become more fuel-efficient, especially hybrid electric vehicles are becoming more common. On the other hand, hydrogen is a chemical energy carrier that can produce electricity up to $39.39 \mathrm{kWh} / \mathrm{kg}$, which surpasses the energy density of most batteries [2]. Hence, considering the benefits of its higher electricity production and zero-emission, hydrogen combined with FC would be the main research interest in the future of vehicles.

Due to the voltage of a FC single cell is relatively low, it must be connected in series to form a stack, which would allow getting appropriate output voltage. Indeed, a typical fuel cell stack is composed of hundreds of cells, such an amount of cells would weaken the system reliability. Furthermore, because of nonlinear voltage-ampere characteristics, the FC output voltage not only depends on the output current but could also be strongly affected by the load. Therefore, a DC/DC converter is mandatory 
to interface FC stack with DC bus. The voltage levels of electrical vehicles (EVs) are decided by the application within the electrical powertrain. The voltage level $270 \mathrm{~V}-540 \mathrm{~V}$ is an attractive choice for most EVs by considering the transmission power and the controllable current [3].

Among the most sort of FC, proton exchange membrane fuel cells (PEMFC) is a prime candidate for vehicle applications, due to its characteristics of high energy conversion efficiency, low operation temperature and high power density [4,5]. It is worth noting that many constraints limit the application of the PEMFC system. As for PEMFC, according to the U.S Department of Energy (DOE) [6], PEMFC technologies face stringent cost and durability requirements for transportation applications. The durability of PEMFC systems operating under automotive conditions should be required at least 5000 hours lifespan (150000 miles equivalent) with less than $10 \%$ loss of performance by the end of life. To obtain better performance for PEMFC during its effective lifespan, some of the researches [7-9] have focused on exploring the maximum power point tracking for the PEMFC to obtain the best performance. However, considering the durability of the PEMFC system, internal and external factors could affect its lifespan. Internal factors mean some failures such as membrane break, cell flooding or drying, poisoning of the catalyst areas and so on that could weaken the reliability of PEMFC. The PEMFC could be assumed as a black box in the situation of external factors, some external characteristics that can indirectly affect the durability of the PEMFC like the current ripple, current overshoot/undershoot and load change are needed to be researched. In this paper, the external factors are the research objects.

Theoretically, the standard boost converter is the cheapest and simplest selection for boosting voltage to the required voltage level [10]. However, due to the lack of redundancy and unfriendly to output current ripple of PEMFC in the practical applications, it would not be selected. For the DC/DC converter, the weight, size and efficiency of the DC/DC converter under the cost and expected lifetime is the primary requirement. The converters that contain transformer has merits in high-voltage ratio, electrical isolation and structural variability, however, it is a tradeoff choice for converter selection in PEMFC vehicle applications. Power density, cost, size and weight all need to be considered, which make the transformer-based converter is not an attractive choice. Among the different types of DC/DC converter used in the FC vehicle [11], the interleaved boost converter (IBC) is a better choice. Due to its interleaved structure, not only the size of the current ripple for FC could be effectively reduced and the frequency of the ripple could be increased several times, but also the stability of the PEMFC system could be guaranteed. Therefore, some researches have been reported for IBC used in the PEMFC applications [12,13].

Nevertheless, it is not a straightforward task to design a controller for IBC with PEMFC when the output voltage and PEMFC current are further considered. On the one hand, taking into account the existence of the non-minimum phase feature in the transfer function from duty cycle to the output voltage, the transfer function contains ac small-signal model, The parameters of the latter have a highly uncertain degree. Some studies [14] that design a double-loop controller based on the proportional-integral (PI) algorithm could solve this issue and the PI controller also has a wide range of applications due to its mature designing process for parameters $[15,16]$. On the other hand, sliding control is another method used in converters because of its strong robustness 
[17-19], in particular, super-twisting sliding mode (STSM) control is a central issue in recent years, because it reduces the chattering compared with traditional sliding mode control (TSMC) in most cases [20]. Authors of [21] use TSMC in a boost converter to minimize the inrush current with DC power. In Ref [22], TSMC is employed by adding a delay-time block to eliminate the chattering in four-phase IBC with super-capacitors. The STSM controller is applied in a flyback converter with verification by using DC power, which is shown in [23]. Ref [24] realized the application of the STSM controller to a boost converter with PEMFC. In Ref [25,26], the STSM controller is used by combing with other controllers to floating interleaved boost convert (FIBC) with DC power. The detailed applications of STSM and TSMC are listed in Table 1.

Table 1 - Comparisons of different related studies

\begin{tabular}{ccccc}
\hline Literature & Converter Type & Controller Type & Application Filed & Verification tool \\
\hline$[21]$ & Boost & TSMC & N/A & DC power \\
{$[22]$} & Four-phase IBC & TSMC & Electric vehicles & Super-Capacitors \\
{$[23]$} & Flyback & STSM control & FC applications & DC power \\
{$[24]$} & Boost & STSM & FC applications & PEMFC \\
{$[25,26]$} & FIBC & STSM control & FC applications & DC power
\end{tabular}

From observing Table 1, although the STSM controller has been employed to the DC-DC converter in the FC application, there is no research focusing on STSM control used in IBC by further considering its influences on FC current ripple and overshoot. Besides, how to balance the robustness in output voltage and performance in FC current brought by STSM controller is also an attractive topic.

In this paper, the STSM controller is designed for a four-phase IBC used with PEMFC, in the meanwhile, the following condition should be considered: (i) 10\% limitation of PEMFC current ripple; (ii) smaller PEMFC current overshoot and undershoot; (iii) better robustness for output voltage. As a comparison, the PI controller is also designed based on ac small-signal model. The main contributions of this paper can be summarized as follows:

(1) Robust control of the interleaved boost converter by using STSM controller for PEMFC.

(2) The design of STSM controller by considering the performance of PEMFC current.

(3) The experimental validation based on a real-time hardware-in-the-loop system (dSPACE1104) under disturbance rejection and voltage tracking is conducted by using PEMFC to verify the effectiveness of the designed STSM controller.

This paper is organized as follows: The mathematical model of PEMFC and four-phase IBC are derived in Section 2. In Section 3, the STSM controller proved by Lyapunov function the typical PI controller based on ac small-signal model are designed. A detailed description of the test bench is introduced in Section 4. Experimental results and discussion are expressed in Section 5. Finally, the major results are summarized in the Conclusion.

2 The PEMFC system modeling

\subsection{PEMFC stack modeling and analysis}


As a kind of primary energy source, hydrogen associated with PEMFC is widely employed in industrial applications, especially in vehicles. Essentially, PEMFC is an electrochemical device that converts chemical energy into electrical energy. Fig. 1 shows the schematic diagram of the PEMFC stack. The reactions that occur at the anode and the cathode respectively can be expressed as [27]:

Anode: $2 \mathrm{H}_{2} \rightarrow 4 \mathrm{H}^{+}+4 e^{-}$

Cathode: $\mathrm{O}_{2}+4 \mathrm{H}^{+}+4 e^{-} \rightarrow 2 \mathrm{H}_{2} \mathrm{O}+$ heat

There are four main layers involved in the PEMFC stack which are flow field plate, cathode gas diffusion, catalyst and proton exchange membrane (PEM) [28]. The hydrogen gas passes through the gas diffusion layer, in the meanwhile, most of them could undergo an oxidation reaction in the effect of catalyst, which is described by (1). Oxygen gas reacts with hydrogen ions and electrons in the cathode, which given by (2).

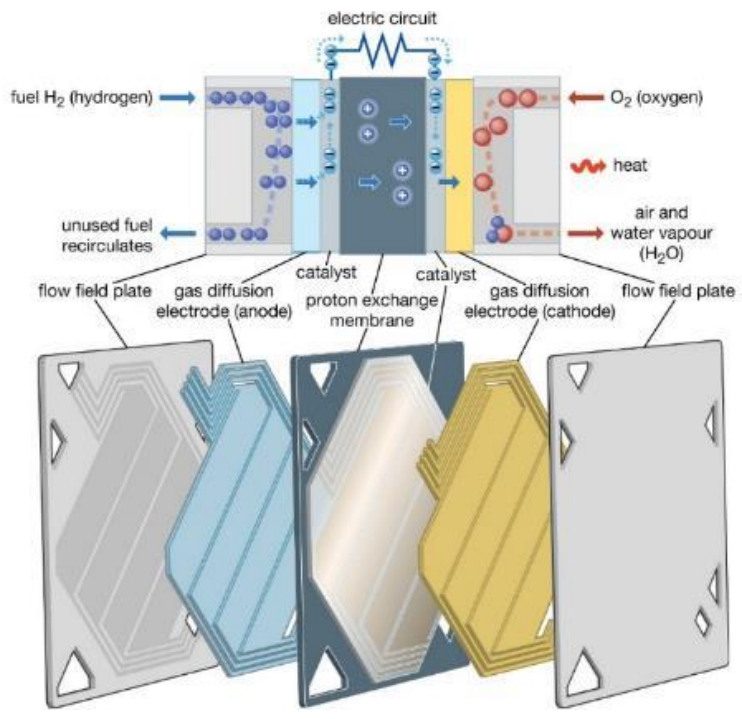

Fig. 1 - The schenmatic diagram of PEMFC

Precise modeling for PEMFC needs to consider the joint of the multi-domain such as electrochemistry, fluid mechanics and thermal [14]. Besides, these modeling usually require lots of data as the foundation. Because of the requirements of higher dynamic characteristics in DC-DC converters, most of these modeling are relatively complex and do not suit the field where PEMFC needs to be combined with a DC-DC converter. In this paper, a simple electrical dynamic model was simulated based on the equivalent electric circuit shown in Fig. 2 by considering some assumptions, the interested readers can refer to [14, 29].

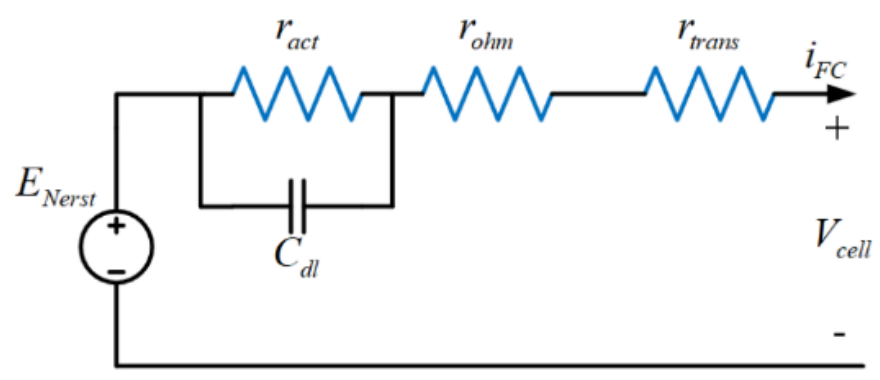

Fig. 2 - Equivalent circuit of a monomer PEMFC 
The brief introduction of the methodology in [29] is recalled below. The equivalent equation of a monomer PEMFC can be expressed in (3).

$$
V_{\text {cell }}=E_{\text {Nerst }}-\Delta v_{\text {act }}-\Delta v_{\text {ohm }}-\Delta v_{\text {trans }}
$$

where $E_{\text {Nerst }}$ is Nerst voltage. Activation loss, ohmic loss and transportation loss correspond to $\Delta v_{\text {act }}, \Delta v_{\text {ohm }}$ and $\Delta v_{\text {trans }}$ respectively. In (3), each variable has its expression where the parameters could be found in the actual datasheet of the used PEMFC. Furthermore, the voltage of the PEMFC stack can be obtained, which is shown in (4).

$$
V_{\text {in }}=n \times V_{\text {cell }}
$$

The PEMFC used in this paper is produced by BALLARD and the product number is Nexa ${ }^{\mathrm{TM}}$ (310-0027), as shown in Fig. 3(a). And the specific parameters can be found in Table. VI.

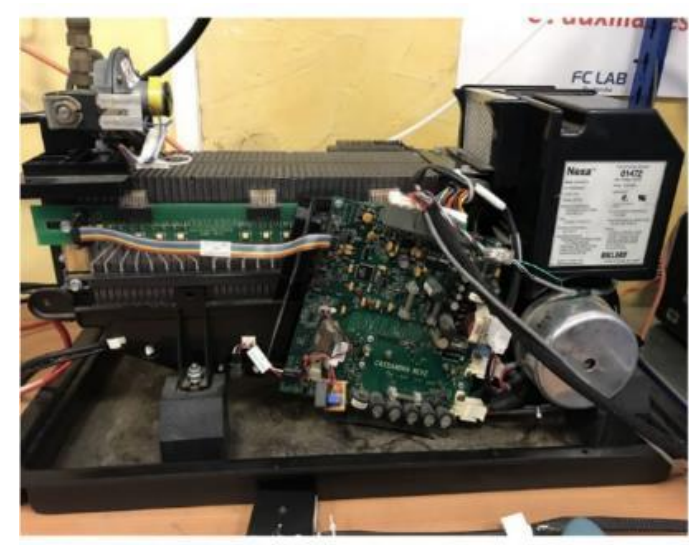

(a)

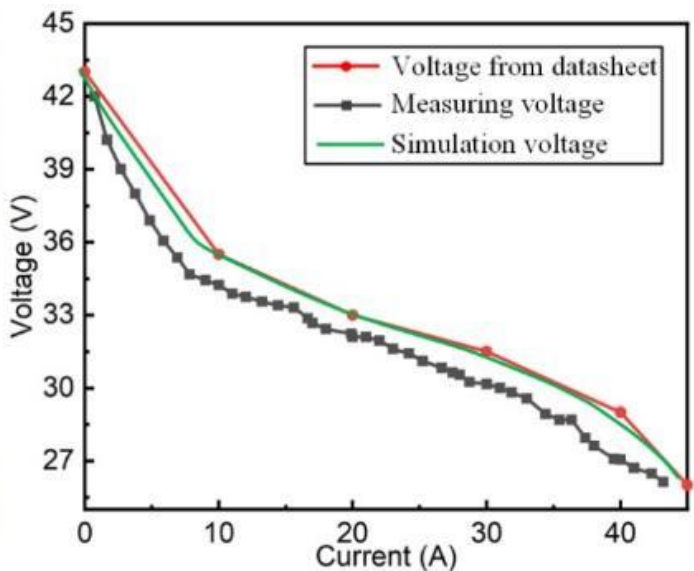

(b)

Fig. 3 - (a) The photo of BALLARD FC, (b) The polarization curves of BALLARD stack

Three curves are revealed in Fig. 3(b), which are voltage from the datasheet, measuring voltage and model simulated. The experimental test consisted of connecting the Ballard FC directly to a programmable electronic load, and measuring the FC output voltage and current while increasing the load consumption. The curves of simulated voltage and voltage from the datasheet have a higher similarity, which means that the PEMFC model restores the polarization curve of the BALLARD stack. However, it should be noted that the curve of measuring voltage still has a large deviation by comparing with the two mentioned curves. The specific performance is that the measuring voltage is smaller than the voltage from the datasheet in the same value of the current. There are many reasons could cause this phenomenon, such as environmental factor or service life. In our research, this phenomenon can be ascribed to long service using. Because of the long-time using (nearly ten years), the performance of the FC stack has dropped severely.

\subsection{Four-phase interleaved boost converter modeling}

The interleaved boost converter can be regarded as the multiple standard boost converter that is shown in Fig. 4(a) connected in parallel. Benefiting from its interleaved structure, Some merits could be obtained:

(1) smaller current stress for switches and diodes; 
(2) smaller inductance volume under the same power;

(3) better fault-tolerant ability;

(4) better inhibition of input current ripple.

The proposed four-phase IBC is shown in Fig. 4(b). Only Continuous Conduction Mode (CCM) is considered in this paper. Four inductors $L_{i}(i=1$ to 4$)$, four power diodes $D_{i}(i=1$ to 4$)$, four power switches $T_{i}(i=1$ to 4$)$ and one capacitor $C$ are contained in this topology. $G_{i}(i=1$ to 4$)$ are the drive signals for the four switches. Since each switch has two states: open and close, there will be sixteen work states in total. To simplify the analysis, the open state of any switch is " 0 ", inversely, the close state corresponds to "1". For example, M1000 means the work state with $T_{1}$ closed and other switches open, as shown in Fig. 4(c). Thus, FC charges $L_{1}$ where its current increase linearly, and supports the energy to the load by combining $L_{2}, L_{3}$ and $L_{4}$. Following Kirchhoff's law, the equation of inductor and capacitor could be listed in (5).

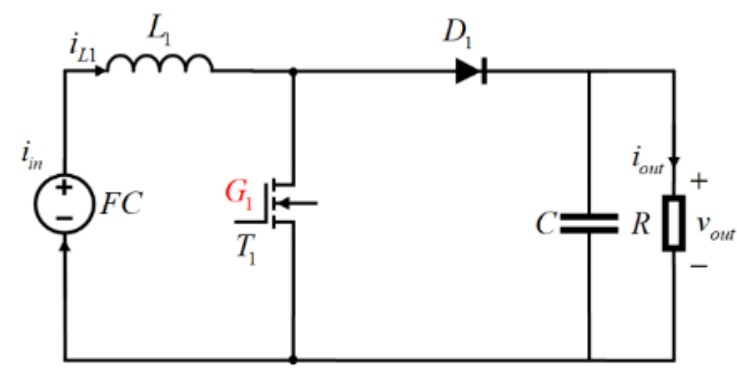

(a)

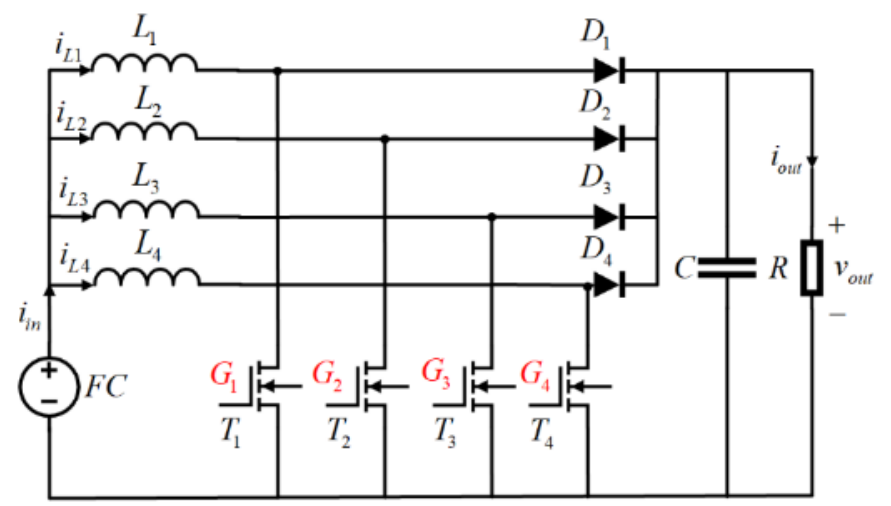

(b)

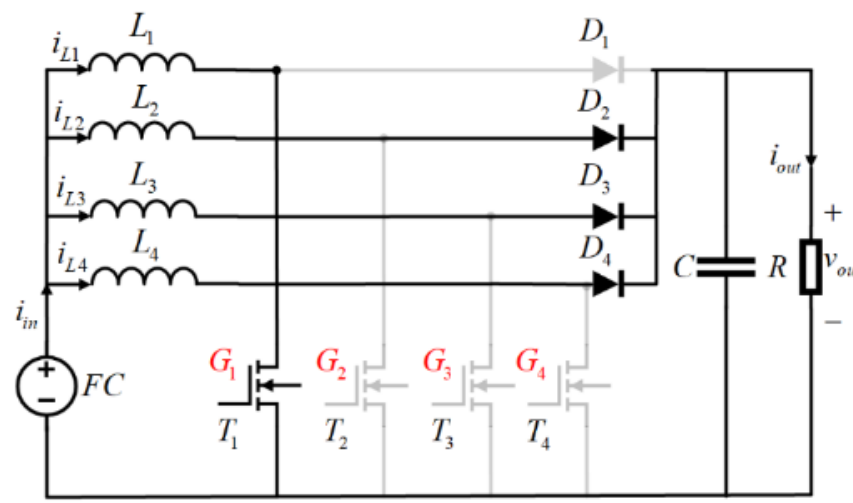

(c)

Fig. 4 - (a) The standard boost converter (b)The topology of four-phase IBC, (c)Work state M1000

$$
\left\{\begin{array}{l}
L_{1} \frac{d i_{L 1}(t)}{d t}=+v_{\text {in }}(t) \\
L_{2(3,4)} \frac{d i_{L 2(3,4)}(t)}{d t}=-v_{\text {out }}(t)+v_{\text {in }}(t) \\
C \frac{d v_{\text {out }}(t)}{d t}=\sum_{i=2}^{4} i_{L i}(t)-\frac{v_{\text {out }}(t)}{R}
\end{array}\right.
$$

$d_{i}(t)(i=1$ to 4$)$ is the duty cycle and corresponding, the opening time of each switch could be obtained $d_{i}(t) T_{S}$. According to the working principle of the four-phase IBC, $T_{s} / 4$ shift angle should exist between every two adjacent phases and the duty 
cycle of each phase should keep at the same value. Combining all the possible sixteen work states, only eight work states can appear in one period. According to the sum of all duty cycles, the actual operation of four-phase IBC could be divided into four situations, which are shown in Table 2.

Table 2 - Four operation situations of four-phase IBC

\begin{tabular}{ccc}
\hline & Condition & Work states \\
\hline Sit. 1 & $0<d_{1}(t)+d_{2}(t)+d_{3}(t)+d_{4}(t) \leq 1$ & $\mathrm{M} 1000 \rightarrow \mathrm{M} 0000 \rightarrow \mathrm{M} 0100 \rightarrow \mathrm{M} 0000 \rightarrow \mathrm{M} 0010 \rightarrow \mathrm{M} 0000 \rightarrow \mathrm{M} 0001 \rightarrow \mathrm{M} 0000$ \\
Sit. 2 & $1<d_{1}(t)+d_{2}(t)+d_{3}(t)+d_{4}(t) \leq 2$ & $\mathrm{M} 1000 \rightarrow \mathrm{M} 1100 \rightarrow \mathrm{M} 0100 \rightarrow \mathrm{M} 0110 \rightarrow \mathrm{M} 0010 \rightarrow \mathrm{M} 0011 \rightarrow \mathrm{M} 0001 \rightarrow \mathrm{M} 1001$ \\
Sit. 3 & $2<d_{1}(t)+d_{2}(t)+d_{3}(t)+d_{4}(t) \leq 3$ & $\mathrm{M} 1011 \rightarrow \mathrm{M} 1001 \rightarrow \mathrm{M} 1101 \rightarrow \mathrm{M} 1100 \rightarrow \mathrm{M} 1110 \rightarrow \mathrm{M} 0110 \rightarrow \mathrm{M} 0111 \rightarrow \mathrm{M} 0011$ \\
Sit. 4 & $3<d_{1}(t)+d_{2}(t)+d_{3}(t)+d_{4}(t) \leq 4$ & $\mathrm{M} 0111 \rightarrow \mathrm{M} 1111 \rightarrow \mathrm{M} 1011 \rightarrow \mathrm{M} 1111 \rightarrow \mathrm{M} 1101 \rightarrow \mathrm{M} 1111 \rightarrow \mathrm{M} 1110 \rightarrow \mathrm{M} 1111$
\end{tabular}

The drive waveforms $G_{i}$ can be obtained by comparing duty cycle $v_{\text {con }_{-} i}(i=1$ to 4$)$ and triangle waveforms $v_{t r i}(i=1$ to 4$)$. As Fig. 5 shows the drive waveforms of Sit. 4, two adjacent drive waveforms have an interval time $T_{S} / 4$, which means $t_{1}+t_{2}=t_{3}+t_{4}=t_{5}+t_{6}=T_{s} / 4$. And in Sit.4, due to the large duty cycle of each switch, there are at least three switches closed simultaneously in one period.

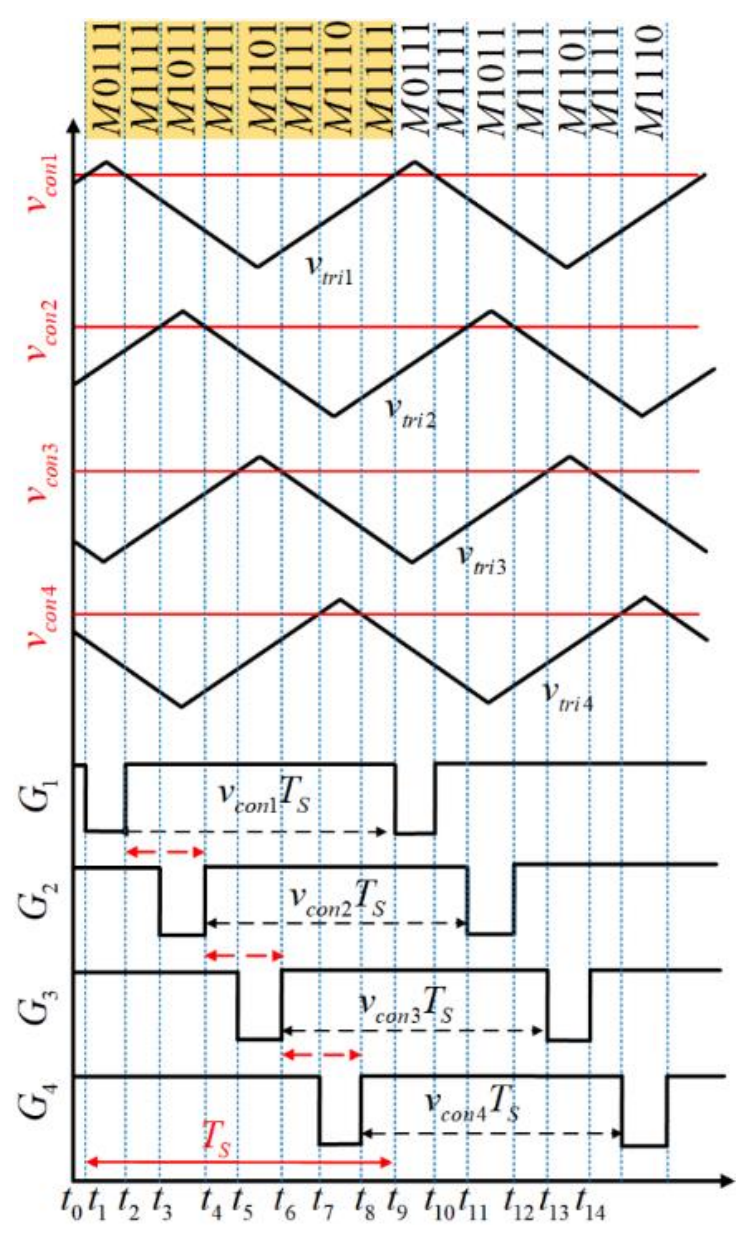

Fig. 5 - Illustrated waveforms of Sit. 4

To obtain the average state-space model of four-phase IBC and further design an effective controller, it is necessary to assume 
the same duty cycle $v_{\text {coni }}=d(t)$ among the different phases in the converter. Then the activation time of specific work states in different situations could be calculated. Table 3 shows the activation time of Sit. 4.

Table 3 - Activation time of Sit. 4

\begin{tabular}{lll}
\hline \multicolumn{1}{c}{ Model } & \multicolumn{1}{c}{ Duration } & Activation time \\
\hline M1111 & $t_{2}-t_{3}=t_{4}-t_{5}=t_{6}-t_{7}=t_{8}-t_{9}$ & $T_{S}[d(t)-3 / 4]$ \\
M0111/M1011/M1101/M1110 & $t_{1}-t_{2}=t_{3}-t_{4}=t_{5}-t_{6}=t_{7}-t_{8}$ & $T_{S}[1-d(t)]$
\end{tabular}

Actually, the same average state-space model of four-phase IBC could be calculated by combining the activation time and the equation of work states in different situations, which is:

$$
\left\{\begin{array}{l}
\frac{d i_{L \mathrm{i}}}{d t}=-\frac{1-d(t)}{L_{i}} v_{\text {out }}+\frac{1}{L_{i}} v_{\text {in }} \\
\frac{d v_{\text {out }}}{d t}=\frac{1-d(t)}{C} \sum_{i=1}^{4} i_{L i}-\frac{1}{R C} v_{\text {out }}
\end{array}\right.
$$

where $i_{L \mathrm{i}}, v_{\text {in }}$ and $v_{\text {out }}$ means the average value in one period. The average value $x$ always contains a DC component $X$ and an AC component $\hat{x}(t)$.

\subsection{The study of the PEMFC current ripple}

As mentioned before, the current ripple $\Delta i_{i n}$ is an important factor affecting the service lifespan and working efficiency of the FC stack. Normally, the value of the PEMFC stack current between the maximum and the minimum is defined as the current ripple $\Delta i_{i n}$. Besides, due to the topology of interleaved boost converter, the FC stack current $i_{\text {in }}$ equals the sum of inductors currents $i_{L i}$, based on that, (7) could be derived

$$
\frac{d i_{i n}}{d t}=\sum_{i=1}^{4} \frac{d i_{L i}}{d t}
$$

To simplify the analysis, assuming $L_{i}=L$, then applying (7) to derive the expression of $\Delta i_{\text {in }}$, a piecewise function could be obtained [10]:

$$
\Delta I_{\text {in }}= \begin{cases}\frac{v_{\text {out }} T_{S}}{L} d(t)[1-4 d(t)] & 0<d(t)<\frac{1}{4} \\ \frac{v_{\text {out }} T_{S}}{L}\left[d(t)-\frac{1}{4}\right][2-4 d(t)] & \frac{1}{4}<d(t)<\frac{1}{2} \\ \frac{v_{\text {out }} T_{S}}{L}\left[d(t)-\frac{1}{2}\right][3-4 d(t)] & \frac{1}{2}<d(t)<\frac{3}{4} \\ \frac{v_{\text {out }} T_{S}}{L}\left[d(t)-\frac{3}{4}\right][4-4 d(t)] & \frac{3}{4}<d(t)<1\end{cases}
$$

Making normalized to (8) by assuming $v_{\text {out }} T_{S} / L$ as a coefficient, the relationship between $\Delta I_{\text {in }} L /\left(v_{\text {out }} T_{S}\right)$ and $d(t) \quad$ could be shown in Fig. 6. To better comparing the current ripple in the IBC, other topologies such as one, two and three-phase IBC are considered in Fig. 6. From observing Fig. 6, the normalized $\Delta I_{\text {in }}$ not only decreases significantly with the number of phases but 
also equal to zero at a certain duty cycle, which would also benefit the FC stack.

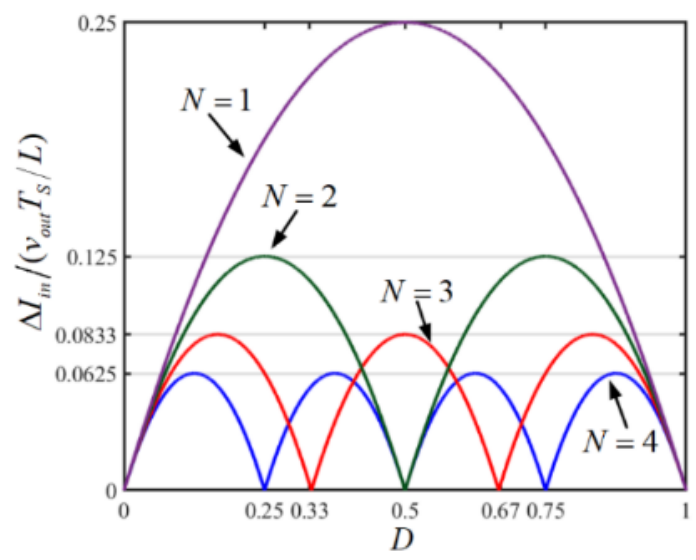

Fig. 6 - Normalized current ripple with the duty cycle

In this paper, four-phase IBC is chosen to apply with FC stack. On the one hand, more phases mean additional switches and diodes are involved, which would cost more and increase the controller complexity. Yet, what cannot be ignored are the benefits brought by the four-phase converter. First, as above mentioned, the current ripple would decrease with the number of phases, which is good for extending the lifespan of the FC stack. Second, four-phase could bring a higher power efficiency compared with two or three phases [30]. Last, more-phase IBC would provide better fault-tolerant ability.

\section{Controller Design}

As mentioned in section 1, an effective method to solve the non-minimum phase of IBC is to transfer the direct voltage control to indirect voltage control by using the inductor current track. In other words, a two-loop control system should be adopted to avoid the issue of unstable output voltage. A two-loop nonlinear controller based on the STSM algorithm is designed for fourphase IBC thoroughly in this section. In addition, the PI as a typical linear algorithm is chosen as a comparison.

\subsection{STSM controller design}

Fig. 7 shows the two-loop controller based on the STSM algorithm. It contains a slow voltage loop, a fast current loop and the control target. For the proposed STSM control, three main procedures are necessary for design: (i) Current loop design and stability proof; (ii) Solving the transfer function of the current closed-loop; (iii) Voltage loop design and stability proof.

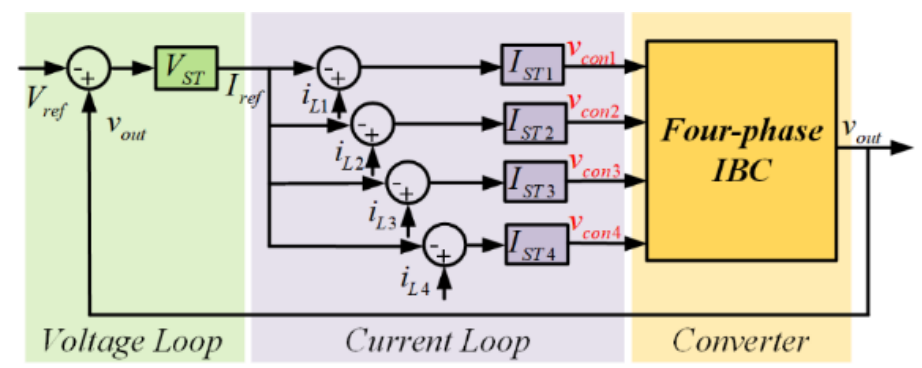

Fig. 7 - The STSM control for four-phase IBC

Step 1: 
The objective of the current loop control is that forcing measuring inductor current $i_{L i}$ follows the reference current $I_{r e f}$ generated from the voltage controller $\left(V_{S T}\right)$. The STSM control law for the current loop ( $\left.I_{S T i}\right)$ can be defined:

$$
u_{i}=-\int_{0}^{t} \alpha_{i} \operatorname{sgn}\left(S_{i}\right) d t-\lambda_{i}\left|S_{i}\right|^{1 / 2} \operatorname{sgn}\left(S_{i}\right)
$$

where $\operatorname{sgn}($.$) is sign function, S_{i}=i_{L i}-I_{\text {ref }}$ is sliding surface, $\lambda_{i}$ and $\alpha_{i}$ are the designed controller parameters $(i=1$ to 4 ). Take the derivative of $S_{i}$, the following equation can be obtained by assuming the same inductor value.

$$
\dot{S}_{i}=-\alpha_{i} \frac{v_{\text {out }}}{L} \int_{0}^{t} \operatorname{sgn}\left(S_{i}\right) d t-\lambda_{i} \frac{v_{\text {out }}}{L}\left|S_{i}\right|^{1 / 2} \operatorname{sgn}\left(S_{i}\right)+\frac{v_{\text {in }}-v_{\text {out }}}{L}
$$

In order to convenient stability proof, some meaningful substitutions can be employed: $\varphi(\mathrm{t})=\left(v_{\text {in }}-v_{\text {out }}\right) / L, k_{1}=\left(v_{\text {out }} \lambda_{i}\right) / L$ $, k_{2}=-\left(v_{\text {out }} \alpha_{i}\right) / L, \quad x=S_{i}$ and $y=\left[-\left(v_{\text {out }} \alpha_{i}\right) / L\right] \int_{0}^{t} \operatorname{sgn}\left(S_{i}\right) d t+\left(v_{\text {in }}-v_{\text {out }}\right) / L$. Afterwards, (10) could be rewritten as:

$$
\left\{\begin{array}{l}
\dot{x}=-k_{1}|x|^{1 / 2} \operatorname{sgn}(x)+\mathrm{y} \\
\dot{y}=-k_{2} \operatorname{sgn}(x)+\dot{\varphi}(\mathrm{t})
\end{array}\right.
$$

A candidate Lyapunov function is established to certificate the stability of (10), which is:

$$
V(x, y)=\xi^{T} P \xi
$$

where $\xi^{T}=\left[\xi_{1}, \xi_{2}\right]=\left[|x|^{1 / 2} \operatorname{sgn}(x), y\right], P=\frac{1}{2}\left[\begin{array}{cc}4 k_{2}+k_{1}^{2} & -k_{1} \\ -k_{1} & 2\end{array}\right]$. First, the established Lyapunov function satisfies $V(0,0)=0$, then $V(x, y)$ can be proved as a positive-definite matrix if $k_{2}>0$ due to its expansion $4 k_{2} x^{2}+\left(k_{1} x-y\right)^{2}+y^{2}$. Afterwards, the derivative of $\xi$ can be obtained: $\dot{\xi}=1 /\left[\left|\xi_{1}\right|(A \xi+B \psi)\right]$, where $\quad A=\left[\begin{array}{cc}-k_{1} / 2 & 1 / 2 \\ -k_{2} & 0\end{array}\right], \quad B=\left[\begin{array}{ll}0 & 1\end{array}\right]^{T}, \quad \psi=|x|^{\frac{1}{2}} \dot{\varphi}$. Furthermore, $\dot{V}(x, y)$ could be derived by combining the above calculations.

$$
\begin{aligned}
\dot{V}(x, y) & =\frac{1}{\left|\xi_{1}\right|}\left[\begin{array}{c}
\xi \\
\psi
\end{array}\right]^{T}\left[\begin{array}{cc}
A^{T} P+P A & P B \\
B^{T} P & 0
\end{array}\right]\left[\begin{array}{c}
\xi \\
\psi
\end{array}\right] \\
& \leq \frac{1}{\left|\xi_{1}\right|}\left\{\left[\begin{array}{c}
\xi \\
\psi
\end{array}\right]^{T}\left[\begin{array}{cc}
A^{T} P+P A & P B \\
B^{T} P & 0
\end{array}\right]\left[\begin{array}{c}
\xi \\
\psi
\end{array}\right]+\xi_{1}^{2} \delta^{2}-\psi^{2}\right\} \\
& =\frac{1}{\left|\xi_{1}\right|}\left[\begin{array}{c}
\xi \\
\psi
\end{array}\right]^{T}\left[\begin{array}{cc}
A^{T} P+P A+\delta^{2} C^{T} C & P B \\
B^{T} P & -1
\end{array}\right]\left[\begin{array}{c}
\xi \\
\psi
\end{array}\right] \\
& \leq \frac{1}{\left|\xi_{1}\right|} \xi^{T} Q \xi
\end{aligned}
$$

where $|\dot{\varphi}| \leq \delta, \quad C=\left[\begin{array}{ll}1 & 0\end{array}\right]$ and 


$$
\begin{aligned}
-Q & =A^{T} P+P A+\delta^{2} C^{T} C+P B B^{T} P \\
& =\left[\begin{array}{cc}
k_{1} k_{2}+\frac{k_{1}^{3}}{2}-\delta^{2}-\frac{k_{1}^{2}}{4} & \frac{k_{1}}{2}-\frac{k_{1}^{2}}{2} \\
\frac{k_{1}}{2}-\frac{k_{1}^{2}}{2} & \frac{k_{1}}{2}-1
\end{array}\right]
\end{aligned}
$$

It can be easily known that $\dot{V}(x, y)$ is a negative-definite matrix when $Q$ is positive, so the condition that satisfies positive property for $Q$ is $k_{1}>2, k_{2}>\left[k_{1}^{3}+\left(4 k_{1}-8\right) \delta^{2}\right] /\left[k_{1}\left(4 k_{1}-8\right)\right]$, after combining the relationship between $k_{1}, k_{2}$ and $\lambda_{i}, \alpha_{i}$, the final conditions that provide the stability of (10) are shown

$$
\lambda_{i}>\frac{2 L}{V_{\text {out }}}, \quad \alpha_{i}>\frac{4 L^{2} \delta^{2}+\lambda_{i}^{2} V_{\text {out }}{ }^{2}}{4 V_{\text {out }}\left(\lambda_{i} V_{\text {out }}-2 L\right)}-\frac{2 \delta^{2} L^{3}}{\lambda_{i} V_{\text {out }}{ }^{2}\left(\lambda_{i} V_{\text {out }}-2 L\right)}
$$

Step 2:

The transfer function of the current closed-loop needs to be calculated. The equivalent control law $u_{e q}$ can be derived by letting $\dot{S}_{i}=d i_{L i} / d t-\dot{I}_{r e f}=0$.

$$
u_{e q}=1+\frac{L \dot{I}_{\text {Lref }}-v_{\text {in }}}{v_{\text {out }}}
$$

Assuming all phases inductor currents are the same and substituting (16) into the last equation of (6), the new equation could be obtained:

$$
\frac{d v_{\text {out }}}{d t}=\frac{4 i_{L} v_{\text {in }}}{C v_{\text {out }}}-\frac{v_{\text {out }}}{R C}-\frac{4 i_{L} L \dot{I}_{\text {ref }}}{C v_{\text {out }}}
$$

The reference current $I_{r e f}$ can be obtained by letting derivatives in (17) equal zero.

$$
I_{r e f}=\frac{V_{o u t}^{2}}{4 R V_{i n}}
$$

Expand (17) by using AC component and DC component of each corresponding variable around the reference current $I_{\text {ref }}$, the following AC equation can be obtained:

$$
V_{\text {out }} \frac{d \hat{v}_{\text {out }}}{d t}=\frac{4 I_{L} \hat{v}_{\text {in }}+4 V_{\text {in }} \hat{i}_{L}}{C}-\frac{2 V_{\text {out }} \hat{v}_{\text {out }}}{R C}-\frac{L V_{\text {out }}^{2}}{R C V_{\text {in }}} \frac{d \hat{i}_{L}}{d t}
$$

Apply Laplace transform to the last equation of (19), the transfer function of the current closed-loop can be derived.

$$
\left.G_{v i}\right|_{v_{\text {in }}(\mathrm{s})=0}=\frac{v_{\text {out }}(\mathrm{s})}{i_{L}(\mathrm{~s})}=\frac{4 R V_{\text {in }}^{2}-L V_{\text {out }}^{2} s}{R C V_{\text {in }} V_{\text {out }} s+2 V_{\text {in }} V_{\text {out }}}=\frac{a-b s}{s+c}
$$

where: $a=\frac{4 V_{\text {in }}}{C V_{\text {out }}}, \quad b=\frac{L V_{\text {out }}}{C R V_{\text {in }}}, \quad c=\frac{2}{R C}$.

Step 3: 
Observing equation (20) and Fig. 7, the current closed-loop is considered as an equivalent plant when designing the voltage loop controller, $I_{\text {ref }}$ is input and $v_{\text {out }}$ is output. The following equation can be obtained based on (20).

$$
\dot{v}_{\text {out }}=-c v_{\text {out }}+a I_{\text {ref }}-b \dot{I}_{\text {ref }}
$$

Note that (21) is one order system, applying the STSM algorithm for voltage loop, the sliding surface is $S_{0}=v_{\text {out }}-V_{\text {ref }}$ and control law is

$$
I_{r e f}=-\int_{0}^{t} \alpha_{0} \operatorname{sgn}\left(S_{0}\right) d t-\lambda_{0}\left|S_{0}\right|^{1 / 2} \operatorname{sgn}\left(S_{0}\right)
$$

where $\alpha_{0}$ and $\lambda_{0}$ are the control parameters of the voltage loop. Furthermore, the derivative of the sliding surface $\dot{S}_{0}$ can be obtained by denoting $f=-c v_{\text {out }}-b \dot{I}_{\text {ref }}$.

$$
\dot{S}_{0}=-a \alpha_{0}|s|^{1 / 2} \operatorname{sgn}(s)-a \lambda_{0} \int \operatorname{sgn}(s) d t+f
$$

The progress of stability proof for (23) is similar with the current loop, which is still building the candidate Lyapunov function. The following inequality can be obtained from the proving process.

$$
\lambda_{0}>\frac{V_{r e f} C}{2 V_{i n}}, \quad \alpha_{0}>\frac{8 V_{i n}^{3} \lambda_{0}^{3}+\left(2 V_{i n} V_{r e f}^{2} C^{2} \lambda_{0}-V_{r e f}^{3} C^{3}\right) \delta_{1}^{2}}{8 V_{i n}^{2} \lambda_{0}\left(4 V_{i n} \lambda_{0}-2 V_{r e f} C\right)}
$$

where $|\dot{f}| \leq \delta_{1}$.

From the above calculations and analyses, four parameters need to be designed: $\alpha_{i}, \lambda_{i}$ for the current loop and $\alpha_{0}, \lambda_{0}$ for the voltage loop. Besides, there are also four parameters $k_{1}, k_{2}$ and $k_{3}, k_{4}$ that are responsible for the stability proof respectively. To obtain the suitable parameters for the controller, for example, like the current loop, the new parameters $\mu_{1}, \mu_{2}$ are introduced.

$$
\lambda_{i} \frac{v_{\text {out }}}{L}=\mu_{1} \sqrt{\delta}, \alpha_{i} \frac{v_{\text {out }}}{L}=\mu_{2} \delta
$$

Based on some researches [31, 32], $\mu_{1}=1.5, \mu_{2}=1.1$ is a tradeoff selection to meet the demands of stability and rapidity for converters. In this way, the following parameters can be obtained: $\lambda_{i}=0.1, \alpha_{i}=200$ for the current loop and $\lambda_{0}=0.05, \alpha_{0}=100$ for the voltage loop.

\subsection{PI controller design}

A double-loop PI controller is proposed as a comparison. The prerequisites of the PI controller is to derive the small-signal model of researched converter. After that, the transfer function $\left(G_{v d}\right)$ of the duty cycle to the output voltage and transfer function $\left(G_{i d}\right)$ of the duty cycle to the inductor current could be obtained by Laplace transform. Last, the controller parameters can be solved by some methods like pole placement and bode diagram. 


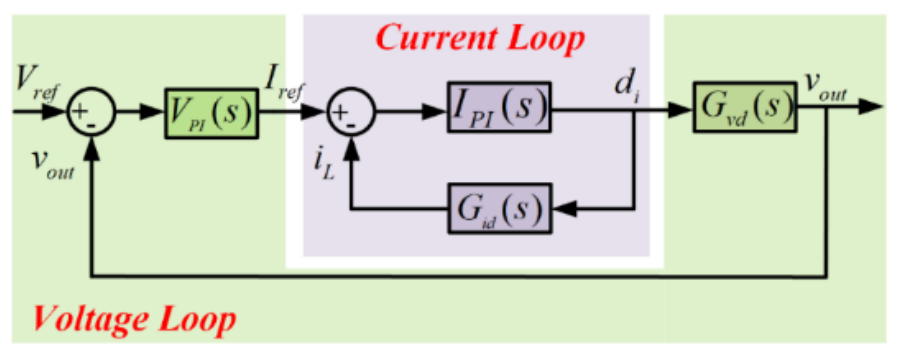

Fig. 8 - The diagram of PT control structure for the IBC

Fig. 8 shows the PT control for the IBC, two loops are contained in this structure. The small-signal model of four-phase IBC can be derived by expanding (6) using their corresponding DC and AC components and ignoring the high order item.

$$
\left\{\begin{array}{l}
\frac{d}{d t} \hat{i}_{L \mathrm{i}}(t)=-\frac{1-D}{L_{i}} \hat{v}_{\text {out }}(t)+\frac{V_{\text {out }}}{L_{i}} \hat{d}(t)+\frac{1}{L_{i}} \hat{v}_{\text {in }}(t) \\
\frac{d}{d t} \hat{v}_{\text {out }}(t)=\frac{1-D}{C} \sum_{i=1}^{4} \hat{i}_{L i}(t)-\frac{1}{R C} \hat{v}_{\text {out }}(t)-\frac{\hat{d}(t)}{C} \sum_{i=1}^{4} I_{L i}
\end{array}\right.
$$

where $D$ is the DC component of the duty cycle $d(t)$. Then the transfer function $G_{i d}(s)$ and $G_{v d}(s)$ can be obtained by making Laplace transform to (26) and assuming $L_{i}=L, i_{L \mathrm{i}}=i_{L} \quad$ simultaneously to design the converter conveniently.

$$
\left\{\begin{array}{l}
G_{i d}(s)=\frac{\hat{i}_{L}(s)}{\hat{d}(s)}=\frac{V_{i n}}{1-D} \bullet \frac{C R s+2}{L C R s^{2}+L s+4(1-D)^{2} R} \\
G_{v d}(s)=\frac{\hat{v}_{\text {out }}(s)}{\hat{d}(s)}=\frac{V_{\text {in }}}{(1-D)^{2}} \bullet \frac{-\rho s+1}{R C \rho s^{2}+\rho s+1}
\end{array}\right.
$$

where $\rho=L /\left[4 R(1-D)^{2}\right]$.

The common designed process is that the fast current loop compensator should be determined to follow the reference variable from the slow voltage loop compensator. Due to the different response speeds between the current loop and the voltage loop, the current closed-loop could be seen as " 1 " when designing the voltage loop compensator. The compensator of the voltage loop and the current loop can be expressed as: $G_{c v}(s)=K_{P v}+K_{I v} / s$ and $G_{c i}(s)=K_{P i}+K_{I i} / s$ respectively.

The parameters selection of the PI controller could be used by the open-loop bode diagram to analyze. On the one hand, two following conditions should be satisfied: (i) the gain margin (GM) should be higher than 0db; (ii) the phase margin (PM) should be higher than $45^{\circ}$. On the other hand, the selected parameters should guarantee a good tradeoff among rapidity, tracking and disturbance rejection. In order to optimize the selected parameters, Particle Swarm Optimization (PSO) [33,34] as a computational method that optimizes a problem by iteratively trying to improve a candidate solution about a given measure of quality. Besides, for a fair comparison, the same conditions should be guaranteed in all experimental tests. Finally, the PI controller parameters can be obtained as: $K_{P i}=0.3, K_{I i}=65$ for the current loop and $K_{P v}=0.5, K_{I v}=25$ for the voltage loop. 


\section{Description of the experimental system}

The testbench was built to perform the experiments and verify the effectiveness of controllers, which is shown in Fig. 9. It consists of: (1) the Ballard FC stack, (2) the interleaved DC-DC converter and electronic load, (3) the circuit of drive signal generating and amplification.
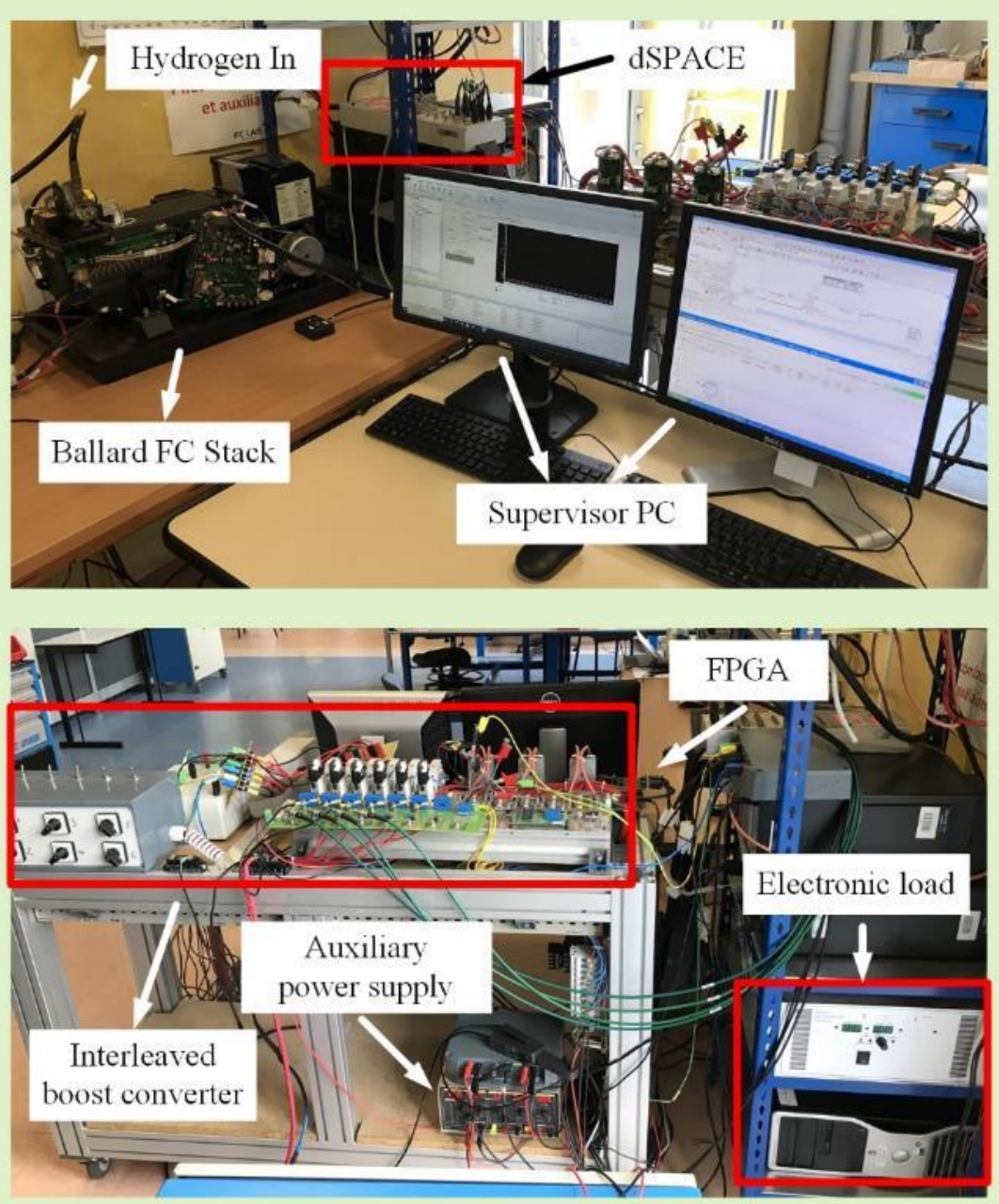

(a)

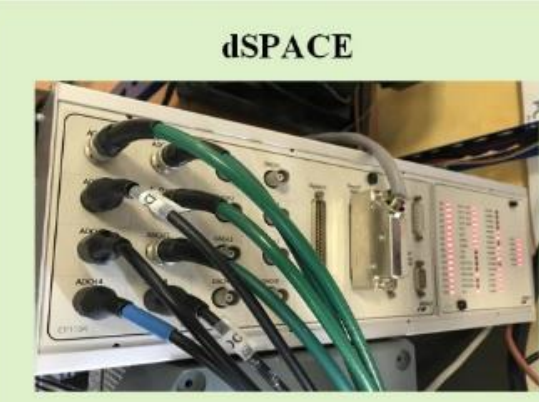

FPGA

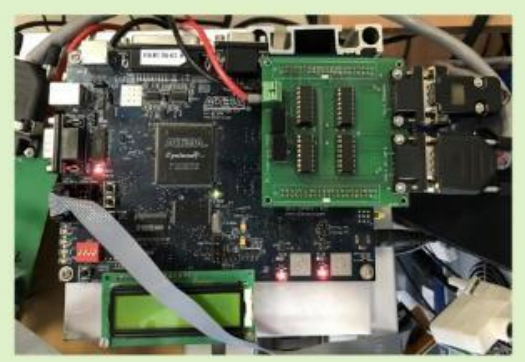

Drive Amplification

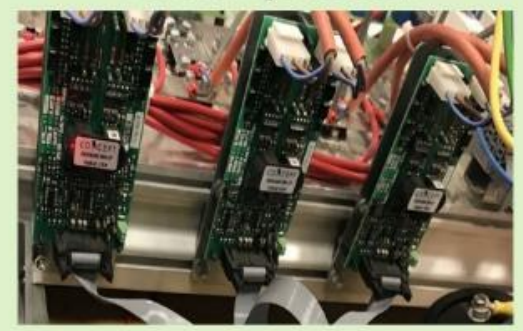

(c)

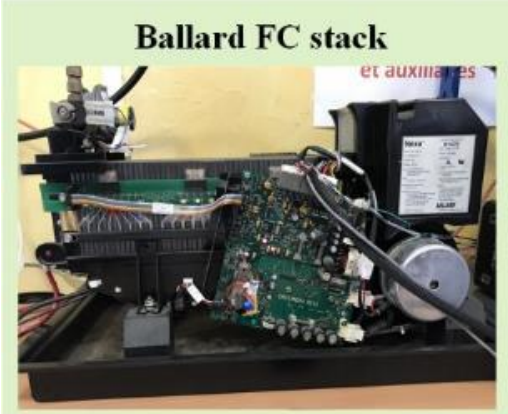

(b)

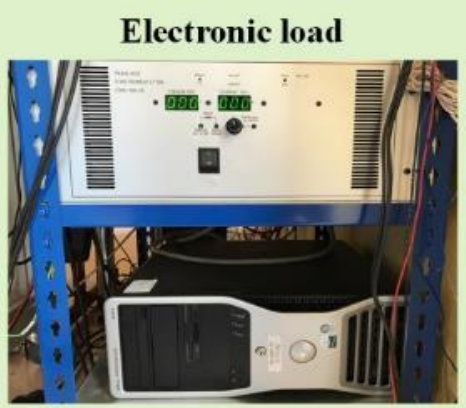

Interleaved boost converter

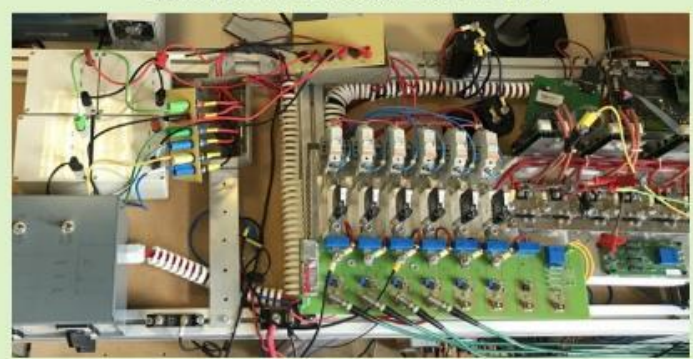

(d)

Fig. 9 - Experiment test bench. (a) the overall picture of the experiment test bench, (b) the Ballard FC stack, (c) the circuit for drive signal generating and amplification, (d) the interleaved DC-DC converter and electronic load 
The specific parameters of the Ballard FC stack are shown in Table 4. The used Ballard FC stack is composed of many cells to reach rated power of $1200 \mathrm{~W}$. Its operating output voltage range from $22 \mathrm{~V}$ to $50 \mathrm{~V}$ and the rated voltage is $26 \mathrm{~V}$. It is noted that an additional power source is necessary to supply the electronic control system of the FC stack when it starts up or shut down. Besides, the maximum power of the FC stack is limited below $1000 \mathrm{~W}$ for protection.

Table 4 - Specifications of Ballard FC stack

\begin{tabular}{|c|c|c|c|}
\hline Items & Requirement & Definition & Quantity \\
\hline \multirow{3}{*}{ Power } & Rated power & Capacity at standard conditions & $1200 \mathrm{~W}$ \\
\hline & \multirow{2}{*}{ voltage } & Voltage at rated power & $26 \mathrm{~V}$ \\
\hline & & Operating voltage range & $22 \mathrm{~V}$ to $50 \mathrm{~V}$ \\
\hline \multirow{3}{*}{ Physical } & Dimensions & $\mathrm{L} \times \mathrm{W} \times \mathrm{H}$ & $56 * 25 * 33 \mathrm{~cm}$ \\
\hline & Mass & Total system mass & $13 \mathrm{~kg}$ \\
\hline & Water & Water produced at rated power & $870 \mathrm{~mL} / \mathrm{hr}$ \\
\hline \multirow{3}{*}{ Fuel } & Purity & Lowest acceptable concentration of hydrogen & $99.99 \% \mathrm{H}_{2}(\mathrm{vol})$ \\
\hline & Pressure & Allowable range of inlet supply pressure ${ }^{2}$ & $70-1720 \mathrm{kPa}(\mathrm{g})$ \\
\hline & Consumption & Maximum fuel consumption at Rated Power & $<18.5$ SLPM \\
\hline \multirow{2}{*}{ Power Conditions } & \multirow{2}{*}{ Current ripple } & Maximum acceptable current ripple at $120 \mathrm{~Hz}$ & \\
\hline & & with respect to average DC net output current & $35 \%$ peak-peak \\
\hline \multirow{2}{*}{ DC power supply } & Voltage & Allowable range of input voltage & $18 \mathrm{~V}$ to $30 \mathrm{~V}$ \\
\hline & Power & Maximum power draw during start-up & $60 \mathrm{~W}$ \\
\hline
\end{tabular}

The DC-DC converter used in the experiments has the ability of six phases as an interface to connect the FC stack with the DC bus. It contains six IGBTs (IXGAN120N60A3D1), six diodes (BYV541V-200), six inductors and two parallel capacitors. The first four phases are employed in this paper and its overall power efficiency can reach $83 \%-85 \%$ after testing. It is noted that the maximum frequency of the selected IGBT model is $5 \mathrm{kHz}$. Theoretically, the best appropriate inductor value can be calculated by using (8) based on $10 \%$ current ripple and $5 \mathrm{kHz}$ switching frequency:

$$
\left\{\begin{array}{l}
L_{\text {to } 48 V}=\left[\left(v_{\text {out }} T_{S}\right) / \Delta I_{\text {in }}\right][d(t)-0.25][2-4 d(t)] \\
L_{\text {to } 70 V}=\left[\left(v_{\text {out }} T_{S}\right) / \Delta I_{\text {in }}\right][d(t)-0.5][3-4 d(t)]
\end{array}\right.
$$

The range of $0.3 \mathrm{mH}-0.35 \mathrm{mH}$ for inductor can be obtained from (28), however, $1 \mathrm{mH}$ inductor is selected by considering the available inductors in the lab, which would satisfy the minimum requirement for inductor further and decrease the current ripple simultaneously. Besides, there are six current sensors (LA55-P) to measure each inductor current and one voltage sensor (LV25P) to grasp the output voltage. These sensors could transform the large electronic signals into suitable signals (-10V to $10 \mathrm{~V})$ for dSPACE1104. The nominal parameters of the DC-DC converter are listed in Table 5. In the actual experiment, the first four phases are chosen to constitute IBC. The model of the used electronic load is C100-100-2K, and its maximum power is $2 \mathrm{~kW}$. 
The maximum limitation of voltage and current are $100 \mathrm{~V}$ and $100 \mathrm{~A}$ respectively. The current absorbed by the electronic load can be set directly through the supervisor PC.

Table 5 - Nominal parameters of the research converter

\begin{tabular}{|c|c|c|c|}
\hline Items & \multicolumn{3}{|c|}{ Parameters Value } \\
\hline Output voltage $V_{\text {out }}$ & \multicolumn{3}{|c|}{$40 \mathrm{~V} \sim 70 \mathrm{~V}$} \\
\hline Inductor $L_{1-4}$ & \multicolumn{3}{|c|}{$1 m H$ (up to $18 \mathrm{~A})$} \\
\hline Output Capacitor $C$ & \multicolumn{3}{|c|}{$6600 u F$} \\
\hline Working Frequency & \multicolumn{3}{|c|}{$5 \mathrm{kHz}$} \\
\hline IGBT & $V_{C E S}$ & $I_{C E \_} \max$ & Frequency \\
\hline IXGN120N60A3D1 & $600 \mathrm{~V}$ & $120 A\left(110^{\circ}\right)$ & $\mathrm{Up}$ to $5 \mathrm{kHz}$ \\
\hline Diode & $I_{F}(R M S)$ & $I_{F}(A V)$ & $V_{R R M}$ \\
\hline BYV541V-200 & $100 A$ & $50 A$ & $200 \mathrm{~V}$ \\
\hline Current sensor & LA55-P & \multicolumn{2}{|c|}{ Conversion ratio } \\
\hline Voltage sensor & LV25-P & \multicolumn{2}{|c|}{ Conversion ratio } \\
\hline
\end{tabular}

The circuit of drive signal generating and amplification contains three parts: dSPACE1104, FPGA EPC12Q240C8 and the drive amplification board. The whole generating and amplification process of drive signals can be briefly summarized: First, dSPACE1104 could produce four PWM signals no shifted after the effect of the designed controller by using the signals collected from current and voltage sensors. Then, the no shifted PWMs are transferred to FPGA which is mainly responsible for producing shifts between two adjacent PWM signals. Last, the widely used drive board (ARCAL2108 and 2SC0108T2G0-17) could amplify four shifted PWMs to satisfy the requirements for driving IGBT correctly. The specific process of PWM generating is shown in Fig. 10(a), and the PWM signals after dSPACE and FPGA are shown in Fig. 10(b) and Fig. 10(c) respectively.

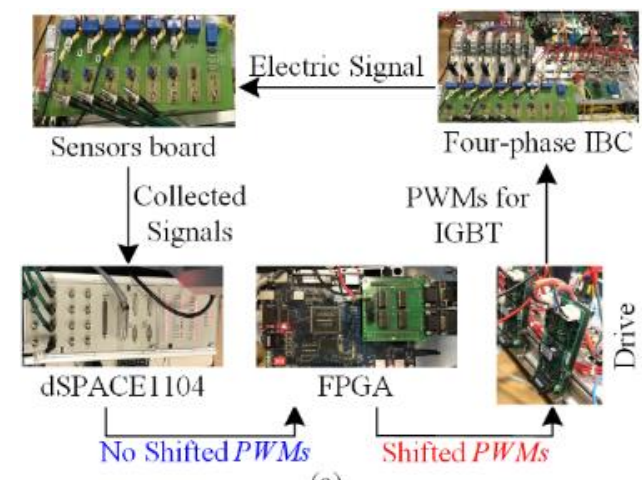

(a)

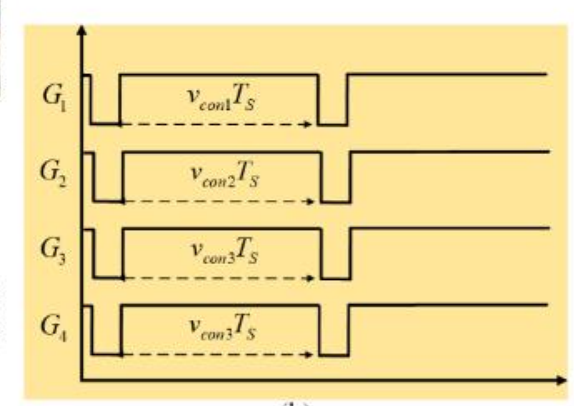

(b)

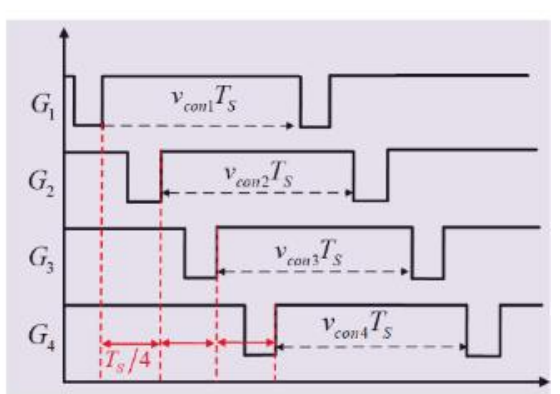

(c)

Fig. 10 - (a)The process of generating shifted PWMs for IGBT, (b)PWMs after dSPACE, (c)PWMs from FPGA 


\section{Experimental results and discussion}

For further verification of the designed controllers for four-phase IBC with FC stack, the experiments based on hardware in the loop platform are performed. Considering the available resources of dSPACE1104 after using six AD inputs and four PWM outputs, the sampling time is set to $1 / 8 \times 10^{-6} s$ for the current loop, which is 10 times faster than the voltage loop.

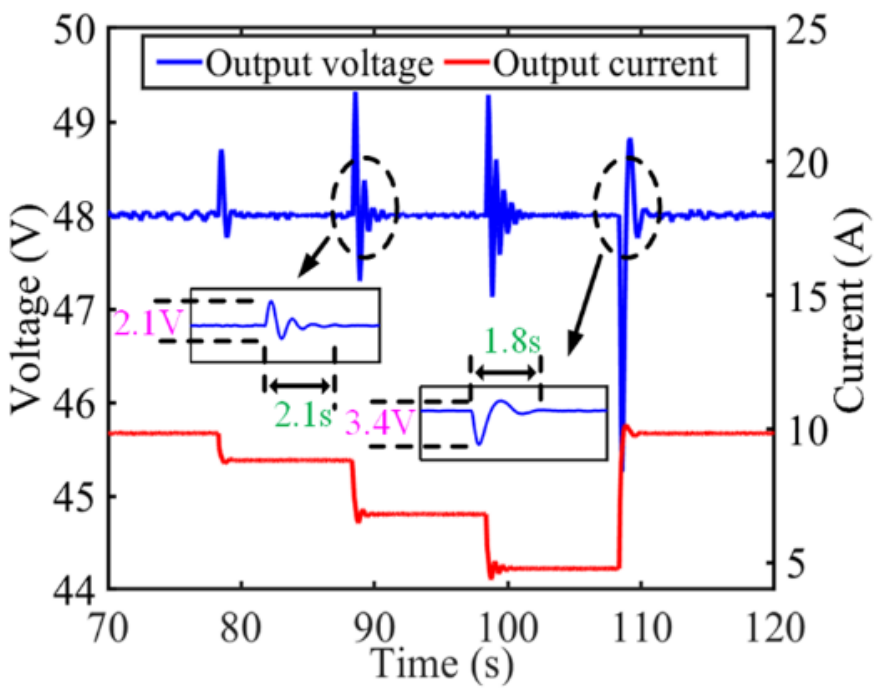

(a)

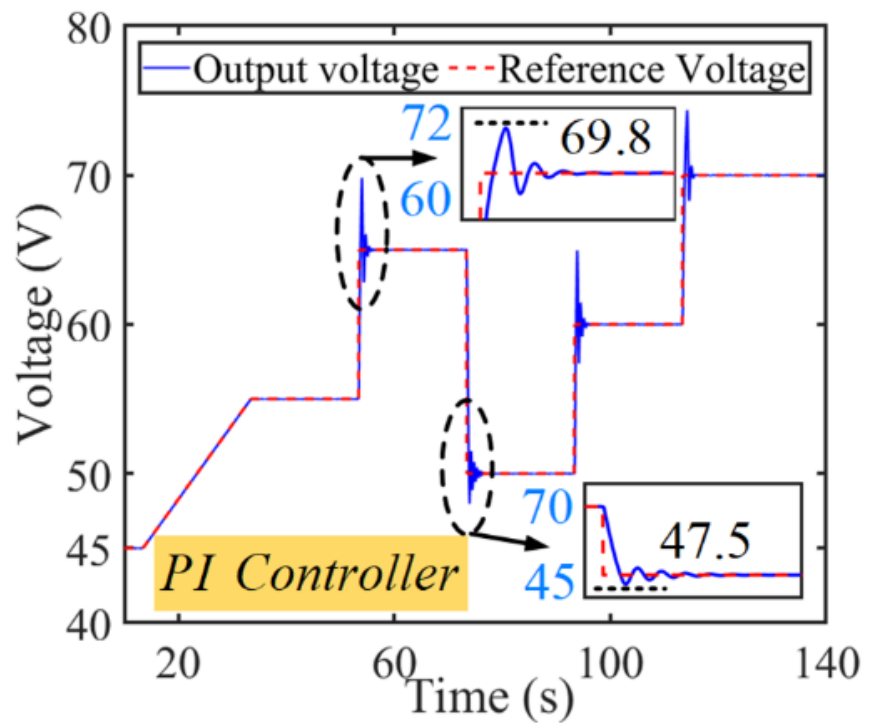

(c)

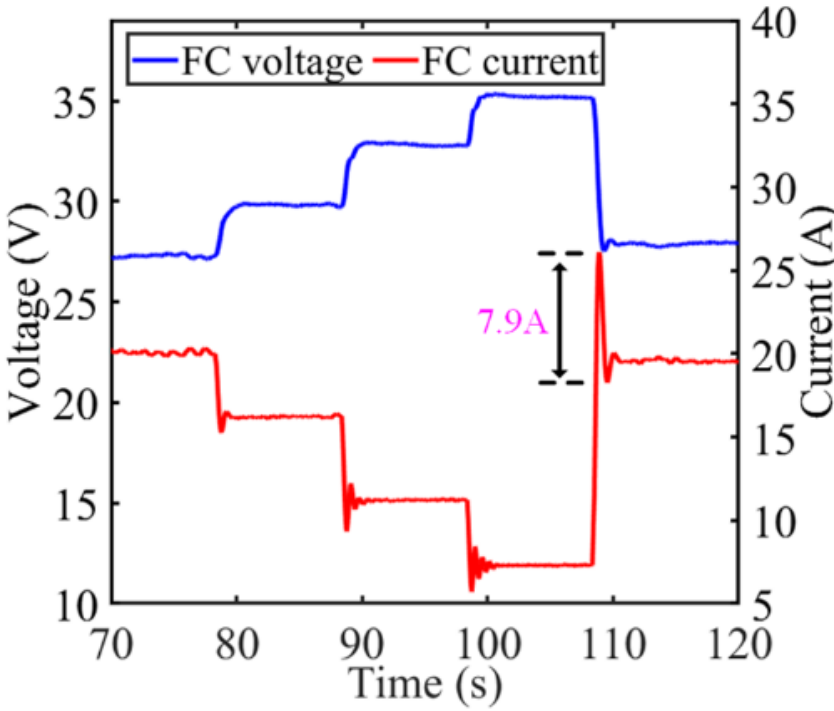

(b)

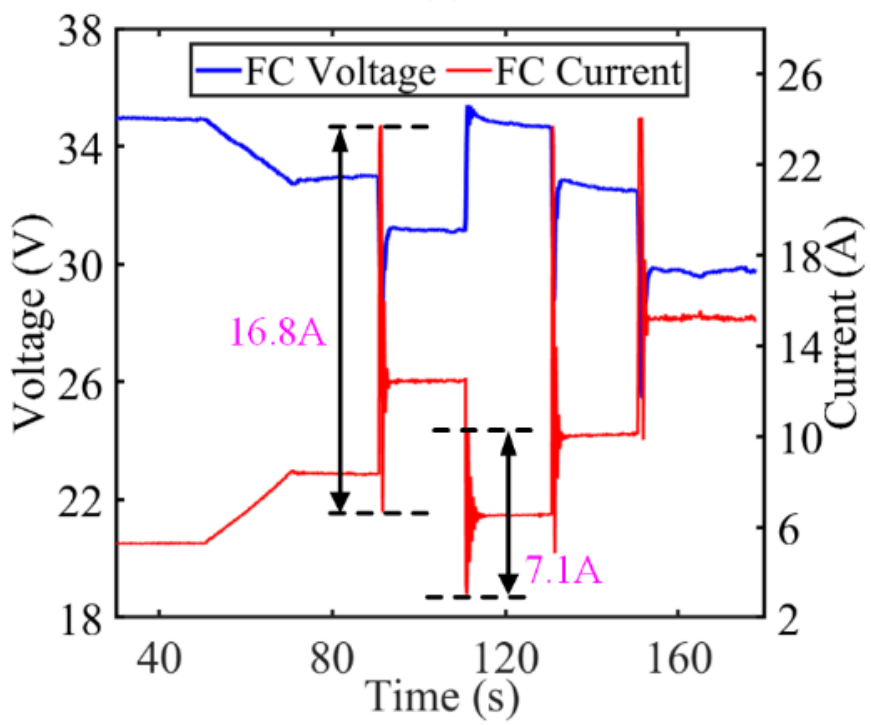

(d)

Fig. 11 - Experimental results based PI controller. (a) output voltage with load change, (b) voltage and current of FC stack with load change,

(c) output voltage with reference change, (d) voltage and current of FC stack with reference change

Fig. 11 shows the experimental results based PI controller. The performance of output voltage \& output current and FC voltage and FC current after load variations are shown in Fig. 11(a) and Fig. 11(b) respectively. As a comparison, the same experiments have been performed by using the STMC controller, which is shown in Fig. 12. From observing Fig. 11(a) and Fig. 12(a), the output voltage could maintain at preset voltage $48 \mathrm{~V}$ when load variations occur, two enlarged detailed figures in Fig.11(a) and Fig. 12(a) correspond to the load disturbance of 150W and 250W respectively. The output voltage tracking a 
variable reference voltage is checked in Fig. 11(c) and Fig. 12(c). The voltage and current of the FC stack are also measured in the meantime, which are shown in Fig. 11(d) and Fig. 12(d).

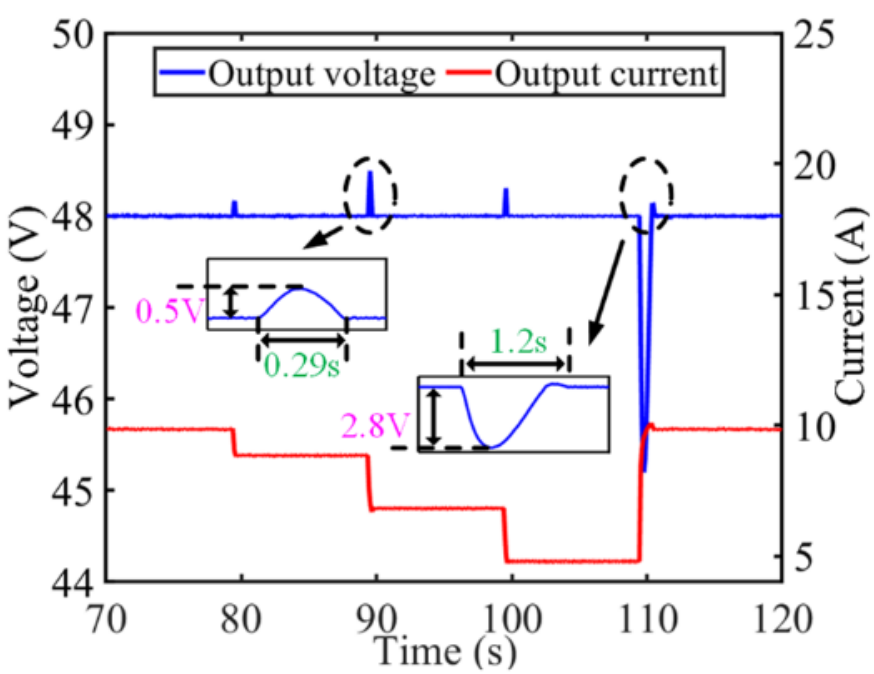

(a)

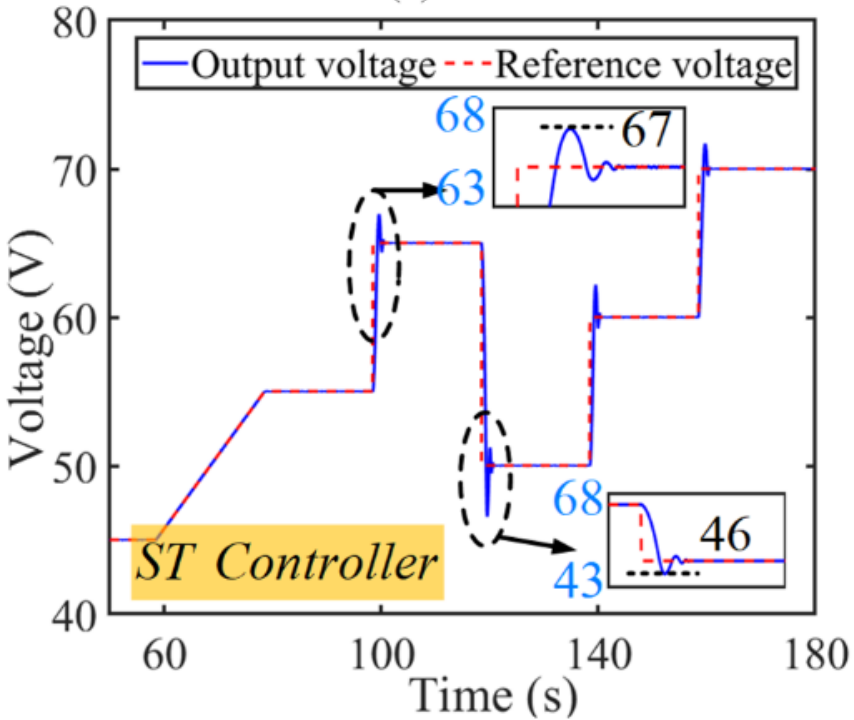

(c)

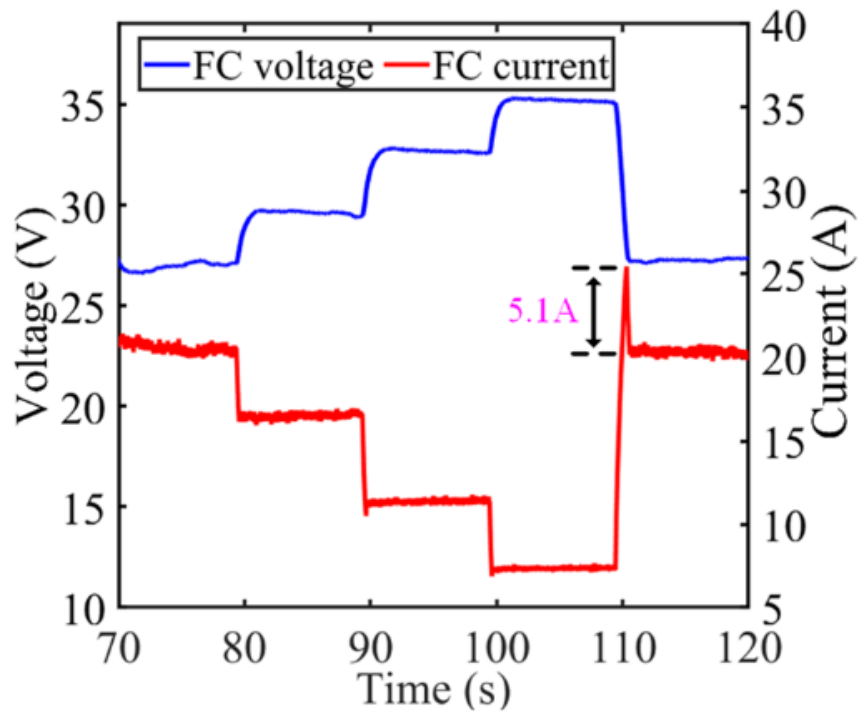

(b)

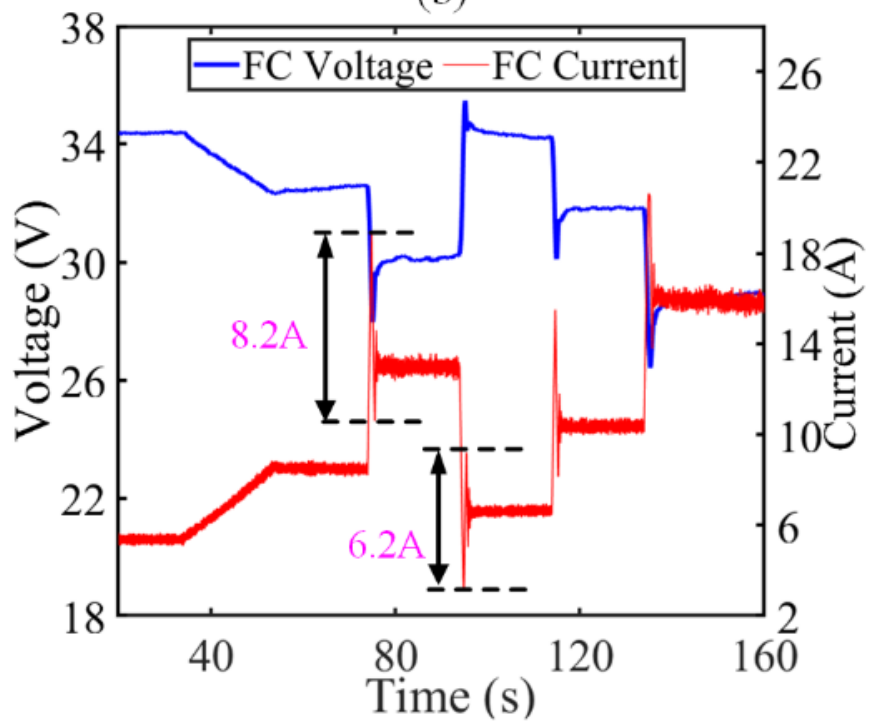

(d)

Fig. 12 - Experimental results based STSM controller. (a) output voltage with load change, (b) voltage and current of FC stack with load change, (c) output voltage with reference change, (d) voltage and current of FC stack with reference change.

From observing and comparing the output voltage between the two different controllers in Fig. 11(a, c) and Fig. 12(a, c), both controllers can maintain stability and guarantee to track the output voltage. However, the two controllers show different performances in specific experiments. The quantitative performances of the output voltage are listed in Table 6. 
Table 6 - Quantitative performances of the output voltage

\begin{tabular}{ccccc}
\hline & Response time & Response time & Voltage overshot & Voltage undershoot \\
Controllers & $150 \mathrm{~W}$ power drop & 250W power rise & $V_{\text {ref }}=65 \mathrm{~V}$ & $V_{\text {ref }}=50 \mathrm{~V}$ \\
& & & & \\
\hline PI controller & $2.1 \mathrm{~s}$ & $1.8 \mathrm{~s}$ & $7.38 \%$ & $5 \%$ \\
STSM controller & $0.29 \mathrm{~s}$ & $1.2 \mathrm{~s}$ & $3.08 \%$ & $8 \%$ \\
\hline
\end{tabular}

From Table 6 , the following conclusions could be obtained: (i) STMC controller has a faster response time that could be shortened by $86 \%$ and 34\% respectively than PI controller; (ii) The voltage ripple could be alleviated largely by using STSM controller when load change; (iii) STSM controller has better inhibition in voltage overshoot (4.38\% promotion), however, PI controller has $3 \%$ superiority in undershoot when reference voltage varies. All in all, the STSM controller has great advantages in disturbance rejection and shows a close effect with the PI controller in voltage overshoot and undershoot inhibition when reference voltage changes.

Table 7 lists the quantitative performances of the FC current ripple by comparing the different controllers shown in Fig. 11(b, d) and Fig. 12(b, d). FC stack current is the main parameter that not only affects the value of FC stack voltage but also plays a vital role to influence the FC lifespan. Specifically, two factors are necessary to be considered in FC stack current: current ripple and current overshoot. As mentioned before, 10\% limitation for FC current ripple is tradeoff value to consider the lifespan of FC, which has been considered when designing the inductor, and the limitation is also good to the controller parameter selection and the working state of FC. As for the current overshoot and undershoot, although no research or work has a clear restriction, limiting the FC current overshoot and undershoot to as small as possible value is significant to maintain the best operational performance for the FC stack. Because the large current overshoot and undershoot maybe cause false protection in the FC stack when its current exceeds the maximum current protection value in a short time.

Table 7 - The quantitative performances of the FC current ripple

\begin{tabular}{cccc}
\hline Item & Current ripple & Current overshot & Current undershoot \\
& $I_{\text {in }}=20 \mathrm{~A}$ & $V_{\text {ref }}=65 \mathrm{~V}$ & $V_{\text {ref }}=50 \mathrm{~V}$ \\
\hline PI controller & $0.3 \mathrm{~A}$ & $16.8 \mathrm{~A}$ & $7.1 \mathrm{~A}$ \\
STSM controller & $0.8 \mathrm{~A}$ & $8.2 \mathrm{~A}$ & $6.2 \mathrm{~A}$
\end{tabular}

Based on Table 7, in terms of the FC current ripple suppression, when the FC current is 20A, the PI controller shows a slight advantage over the STSM controller (0.3A vs 0.8A), which are all acceptable. First, $1.5 \%$ for PI and $4 \%$ for STSM current ripple are satisfied the requirement of $10 \%$ FC current ripple. Then, the reason for this situation is the chattering effect brought by the sliding mode [35]. Although the STSM as a higher-order sliding mode could weaken the chattering effect largely in some applications [20], it cannot be eliminated thoroughly. In terms of FC current overshoot and undershoot, the STSM controller 
could significantly reduce overshoot and undershoot compared with the PI controller in the condition of the variable reference voltage.

Combing the performance of two controllers in output voltage and FC stack current, the STMC controller is more suitable for the FC vehicle applications. The STSM controller shows strong robustness, especially in faster response time and better overshoot/undershoot inhibition effect. Although some deficiencies such as FC current ripple suppression are existed compared to the PI controller, its performance is acceptable and still satisfies the demand of FC stacks.

\section{Conclusion}

In this paper, the STSM controller was designed by considering the robustness of the output voltage and the performance of the PEMFC current. The following control targets were obtained: stable output voltage, strong robustness of the output voltage, sharing PEMFC current evenly, 10\% limitations of the PEMFC current ripple and inhibition of PEMFC current. First, a simple electronic model of PEMFC based on previous research was introduced and a precise average state-space model of four-phase IBC based on the analysis of all possible work states were designed. Then the STSM controller proved by Lyapunov's stability theory was designed by considering all requirements. Last, a PEMFC system with four-phase IBC was built to verify the effectiveness of the controllers by using dSPACE and FPGA boards.

In sum, the designed STSM controller shows strong robustness in response time for the load disturbance and overshoot/undershoot inhibition for FC current compared with the PI controller, which is good for extending the lifespan of the FC stack and providing the stable operation of the FC system. Although the FC current ripple would increase slightly by using the STSM controller compared to the PI controller, it is acceptable and still meets the limitation of the current ripple below $10 \%$.

\section{ACKNOWLEDGMENT}

The support from Chinese Scholarship Council (CSC, Number: 201806290289) and MobyPost project funded under the Grant Agreement No.256834 by the European Union's seventh Framework program (FP7/2007-2013) for the Fuel Cell and Hydrogen Joint 320 Technology Undertaking (http://mobypostproject.eu/), are kindly acknowledged.

\section{REFERENCES}

[1] E.L.V. Eriksson, E.MacA. Gray. Optimization and integration of hybrid renewable energy hydrogen fuel cell energy systems-A critical review. Appl. Energy 2017, 202, 348-364. https://doi.org/10.1016/j.apenergy.2017.03.132.

[2] Manoharan Y, et al. Hydrogen fuel cell vehicles; current status and future prospect. Applied Sciences, 2019, 9(11): 2296. https://doi.org/10.3390/app9112296.

[3] Kirubakaran A, Jain S, Nema R K. A review on fuel cell technologies and power electronic interface. Renewable and Sustainable Energy Reviews, 2009, 13(9): 2430-2440. https://doi.org/10.1016/j.rser.2009.04.004.

[4] ZVEI-German Electrical and Electronic Manufacturers' Association. Voltage Classes for Electric Mobility. 2013. https://www.zvei.org/fileadmin/user_upload/Presse_und_Medien/Publikationen/2014/april/Voltage_Classes_for_Electri 
c_Mobility/Voltage_Classes_for_Electric_Mobility.pdf.

[5] Fathy A, Abdelkareem M A, Olabi A G, et al. A novel strategy based on salp swarm algorithm for extracting the maximum power of proton exchange membrane fuel cell. International Journal of Hydrogen Energy, 2021, 46(8): 6087-6099. https://doi.org/10.1016/j.ijhydene.2020.02.165.

[6] U.S. Department of Energy, Fuel Cell Technologies Office. Multi-Year Research, Development, and Demonstration Plan. Chapter 3.4, 2014,pp. 10-11. https://www.energy.gov/sites/prod/files/2014/12/f19/fcto_myrdd_full_document.pdf.

[7] Srinivasan S, Tiwari R, Krishnamoorthy M, et al. Neural network based MPPT control with reconfigured quadratic boost converter for fuel cell application. International Journal of Hydrogen Energy, 2021, 46(9): 6709-6719. https://doi.org/10.1016/j.ijhydene.2020.11.121.

[8] Harrag A, Rezk H. Indirect P\&O type-2 fuzzy-based adaptive step MPPT for proton exchange membrane fuel cell. Neural Computing and Applications, 2021: 1-14. https://doi.org/10.1016/10.1007/s00521-021-05729-w.

[9] Derbeli M, Charaabi A, Barambones O, et al. High-Performance Tracking for Proton Exchange Membrane Fuel Cell System PEMFC Using Model Predictive Control. Mathematics, 2021, 9(11): 1158. https://doi.org/10.3390/math9111158.

[10] Mishra H, Ray S, Dixit T V. Design of Double Loop CDM Controllers for Proton Exchange Membrane Fuel Cell Fed DCDC Boost Converter Under Wide Source and Load Variations. International Journal of Control, Automation and Systems, 2021, 19(5): 1873-1881. https://doi.org/10.1016/10.1007/s12555-020-0237-8.

[11] Kolli A, Gaillard A, De Bernardinis A, et al. A review on DC/DC converter architectures for power fuel cell applications. Energy Conversion and Management, 2015, 105: 716-730. https://doi.org/10.1016/10.1016/j.enconman.2015.07.060.

[12] Slah F, Mansour A, Hajer M, et al. Analysis, modeling and implementation of an interleaved boost DC-DC converter for fuel cell used in electric vehicle. International journal of hydrogen energy, 2017, 42(48): 28852-28864. https://doi.org/10.1016/j.ijhydene.2017.08.068.

[13] Farhani S, N'Diaye A, Djerdir A, et al. Design and practical study of three phase interleaved boost converter for fuel cell electric vehicle. Journal of Power Sources, 2020, 479: 228815. https://doi.org/10.1016/j.jpowsour.2020.228815.

[14] Somkun S, Sirisamphanwong C, Sukchai S. A DSP-based interleaved boost DC-DC converter for fuel cell applications. International journal of hydrogen energy, 2015, 40(19): 6391-6404. https://doi.org/10.1016/j.ijhydene.2015.03.069.

[15] Kabalo M, Paire D, Blunier B, et al. Experimental evaluation of four-phase floating interleaved boost converter design and control for fuel cell applications. IET power electronics, 2013, 6(2): 215-226. https://doi.org/10.1049/ietpel.2012.0221.

[16] De Bernardinis A, Péra M C, Garnier J, et al. Fuel cells multi-stack power architectures and experimental validation of 1 $\mathrm{kW}$ parallel twin stack PEFC generator based on high frequency magnetic coupling dedicated to on board power unit. Energy Conversion and Management, 2008, 49(8): 2367-2383. https://doi.org/10.1016/j.enconman.2008.01.022. 
[17] Utkin V. Sliding mode control of DC/DC converters. Journal of the Franklin Institute, 2013, 350(8): $2146-2165$. https://doi.org/10.1016/j.jfranklin.2013.02.026.

[18] Napole C, Derbeli M, Barambones O. A global integral terminal sliding mode control based on a novel reaching law for a proton exchange membrane fuel cell system. Applied Energy, 2021, $301: \quad 117473$. https://doi.org/10.1016/j.apenergy.2021.117473.

[19] Sankar K, Saravanakumar G, Jana A K. Nonlinear multivariable control of an integrated PEM fuel cell system with a DCDC boost converter. Chemical Engineering Research and Design, 2021, 167: 141-156. https://doi.org/10.1016/j.cherd.2021.01.011.

[20] Álvarez Rodríguez S. Robustness vs Chattering-effect study for the Sliding Mode Control. Nova scientia, 2019, 11(23). https://doi.org/10.21640/ns.v11i23.1972.

[21] Martínez-Salamero L, García G, Orellana M, et al. Start-up control and voltage regulation in a boost converter under sliding-mode operation. IEEE Transactions on industrial electronics, 2012, 60(10): 4637-4649. https://doi.org/10.1109/TIE.2012.2210375.

[22] Ayoubi Y, Elsied M, Oukaour A, et al. Four-phase interleaved DC/DC boost converter interfaces for super-capacitors in electric vehicle application based on advanced sliding mode control design. Electric Power Systems Research, 2016, 134: 186-196. https://doi.org/10.1016/j.epsr.2016.01.016.

[23] Wu Y, Huangfu Y, Ma R, et al. A strong robust DC-DC converter of all-digital high-order sliding mode control for fuel cell power applications. Journal of Power Sources, 2019, 413: 222-232. https://doi.org/10.1016/j.jpowsour.2018.12.049.

[24] Derbeli M, Barambones O, Ramos-Hernanz J A, et al. Real-time implementation of a super twisting algorithm for PEM fuel cell power system. Energies, 2019, 12(9): 1594. https://doi.org/10.3390/en12091594.

[25] Zhuo S, Gaillard A, Paire D, et al. Design and control of a floating interleaved boost dc-dc converter for fuel cell applications. IECON, Washington, IEEE, 2018: 2026-2031. https://doi.org/10.1109/IECON.2018.8591304.

[26] Huangfu Y, Zhuo S, Chen F, et al. Robust voltage control of floating interleaved boost converter for fuel cell systems. IEEE Transactions on Industry Applications, 2017, 54(1): 665-674. https://doi.org/10.1109/TIA.2017.2752686.

[27] Schumm Brooke. Fuel cell. Encyclopedia Britannica. 7 April 2021. https://www.britannica.com/technology/fuel-cell.

[28] Blal M, Benatiallah A, NeÇaibia A, et al. Contribution and investigation to compare models parameters of (PEMFC), comprehensives review of fuel cell models and their degradation. Energy, 2019, 168: 182-199. https://doi.org/10.1016/j.energy.2018.11.095

[29] Wang C, Nehrir M H, Shaw S R. Dynamic models and model validation for PEM fuel cells using electrical circuits. IEEE transactions on energy conversion. 2005, 20(2): 442-451. https://doi.org/10.1109/TEC.2004.842357.

[30] Farhani S, N'Diaye A, Djerdir A, et al. Design and practical study of three phase interleaved boost converter for fuel cell 
electric vehicle. Journal of Power Sources, 2020, 479: 228815. https://doi.org/10.1016/j.jpowsour.2020.228815

[31] Y. Shtessel, C. Edwards, L. Fridman, and A. Levant, Sliding Mode Control and Observation: New York, NY, USA: Springer, 2014. https://doi.org/10.1007/978-0-8176-4893-0_6.

[32] A. Levant. Robust exact differentiation via sliding mode technique. Automatica, vol. 34, no. 3, pp. 379-384, 1998. https://doi.org/10.1016/S0005-1098(97)00209-4.

[33] Golbon-Haghighi, Mohammad-Hossein; Saeidi-Manesh, Hadi; Zhang, Guifu; Zhang, Yan. Pattern Synthesis for the Cylindrical Polarimetric Phased Array Radar (CPPAR). Progress in Electromagnetics Research, 2018, 66: 87-98. https://doi.org/10.2528/PIERM18011016.

[34] Dali A, Abdelmalek S, Bakdi A, et al. A novel effective nonlinear state observer based robust nonlinear sliding mode controller for a $6 \mathrm{~kW}$ Proton Exchange Membrane Fuel Cell voltage regulation. Sustainable Energy Technologies and Assessments, 2021, 44: 100996. https://doi.org/10.1016/j.seta.2021.100996.

[35] Utkin V, Lee H. Chattering problem in sliding mode control systems. International Workshop on Variable Structure Systems, 2006. VSS'06. IEEE, 2006: 346-350. https://doi.org/10.1109/VSS.2006.1644542 